\title{
ANATOMICAL CONSIDERATION FOR POSTERIOR ATLANTOAXIAL TRANSARTICULAR SCREW FIXATION FROM REFORMATTED TWO- DIMENSIONAL CT IMAGES
}

\author{
Phanunan Sasiprapha, Sompob Poopitaya \\ Department of Orthopaedic Surgery, Phramongkutklao College of Medicine, Bangkok, Thailand
}

Background: Posterior transarticular C1-C2 fixation by screw is a widely used technique to correct atlantoaxial instability. However, the screw trajectory must be precise because the adjacent vital organs include the spinal cord and vertebral artery in the transverse foramen. Due to the lack of an objective measuring method, clarifying the range of the safe zone of screw trajectory in both the sagittal and coronal planes is important.

Objectives: To clarify the safe zone and ideal trajectory for screw fixation ensuring safety and without violating the transverse foramen and spinal canal.

Methods: Radiographs of the normal upper cervical spine in sagittal and coronal reconstruction CT scans from the entry point of the screw on $\mathrm{C} 2$ was performed and the safe zone for the screw path was drawn. The points of screw intersection on the superior articular surface of $\mathrm{C} 2$ were measured from the posterior rim of the superior articular surface of $\mathrm{C} 2$ then the safe zone of the screw in the coronal plane was drawn in the coronal oblique plane along the screw direction.

Results: Average safe zone in the sagittal plane was $51.6^{\circ}-61.2^{\circ}$ relative to the superior articular surface of $\mathrm{C} 2$ and the safe zone in the coronal view was medially $9.5^{\circ}$ and laterally $4.2^{\circ}$ relative to the midline of the spinous process. The safe zone and ideal screw trajectory should intersect $\mathrm{C} 2$ at 8.03 and $4.5 \mathrm{~mm}$ from the posterior rim of the superior articular surface on $\mathrm{C} 2$.

Conclusion: The result of this study showed the range of the safe zone of the posterior atlantoaxial screw trajectory that guides to minimize the risk of misdirection and violating the transverse foramen by the screw. The areas on the superior articular surface of $\mathrm{C} 2$ intersected by the trajectories making the longest paths are guides to purchase the longest path of bone to achieve more stability and pullout strength.

Keywords : Atlantoaxial, transarticular screw, Cervical Spine

J Southeast Asian Med Res 2017; 1; 44-47.

http://www.jseamed.org

\section{Correspondence to:}

Poopitaya S, Department of Orthopedic Surgery, Phramongkutklao College of Medicine, Bangkok, Thailand E-mail : sompobpoo@gmail.com 


\section{Background}

Posterior transarticular screw fixation was pioneered by Magerl and Seeman in the $1970 \mathrm{~s}{ }^{(1)}$ This surgical technique has been an accepted method to promote immediate rigid fixation for atlantoaxial instability, obviating the need for rigid external bracing. ${ }^{(2)}$

However, this technique is inherently demanding because the tolerance for error in this region of the spine is low and because small variations are always located in the anatomy of this region. Superior and precise measurement is mandatory to correct the trajectory of the screw and avoid complications of the vital and critical structures in this area such as the vertebral artery and spinal cord.

The limitation of this technique is the lack of an objective method to clarify the direction of this screw. In this study, we used a two dimension $1 \mathrm{~mm}$ slice reformatted CT scan to measure the safe zone of the screw trajectory and objectified by measuring the location of point of the screw intersection on the superior surface of $\mathrm{C} 2$.

\section{Objectives}

1. To clarify the safe zone for screw trajectory in both sagittal and coronal views that are purchased in $\mathrm{Cl}$ and do not violate the vertebral foramen.

2. To clarify the ideal screw trajectory and length that creates the longest path to provide the greatest pullout strength for screw fixation.

3. Measuring point of safe and ideal screw transected on $\mathrm{C} 2$ superior articular surface to use for objective reference of the screw trajectory.

\section{Study populations}

We studied 75 human adult cervical CT scans of both sexes ( 40 males, 35 females) with a mean age of 53 years from the Radiology Department, Phramongkutklao College of Medicine.

The inclusion criteria were

(1) they no longer present the pathology of the upper cervical spine and

(2) age $>20$ years and data will be excluded for prior cervical spine fracture or anomaly of the cervical spine.

\section{Measurements}

Reformatted one-millimeter slices in 75 samples were reconstructed. The sagittal and coronal oblique reconstruction were made at the standard entry point of the atlantoaxial screw ( $2 \mathrm{~mm}$ superior and medial from the $\mathrm{C} 2$ to $\mathrm{C} 3$ facet joint)

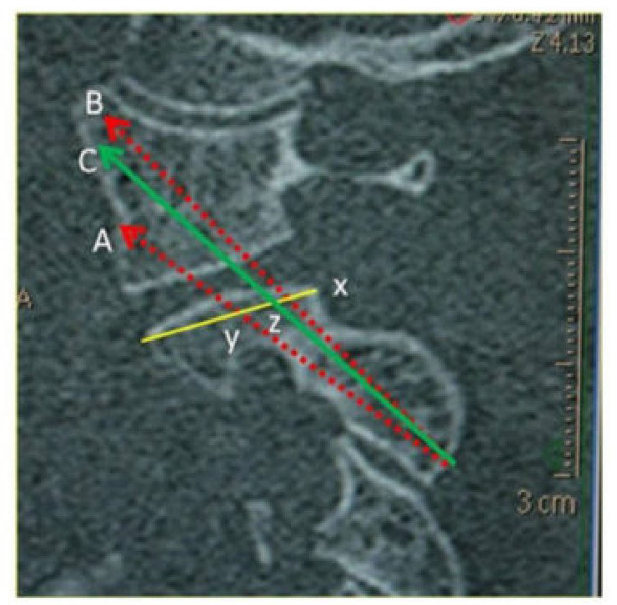

Fig. 1 Sagittal view reconstruction of atlanloaxial complex

From Fig. 1: Three of the $3.5 \mathrm{~mm}$ screw trajectories were simulated. A and B arrows show the safest caudal and cephalad angle of the screw. The $\mathrm{C}$ arrow shows the ideal path of the screw, the safest and longest path to obtain the most pullout strength. The $\mathrm{XY}$ distance is a safe zone for the screw trajectory reference on the $\mathrm{C} 2$ articular surface. The $\mathrm{XZ}$ distance is the point of the ideal screw transected on the $\mathrm{C} 2$ articular surface.

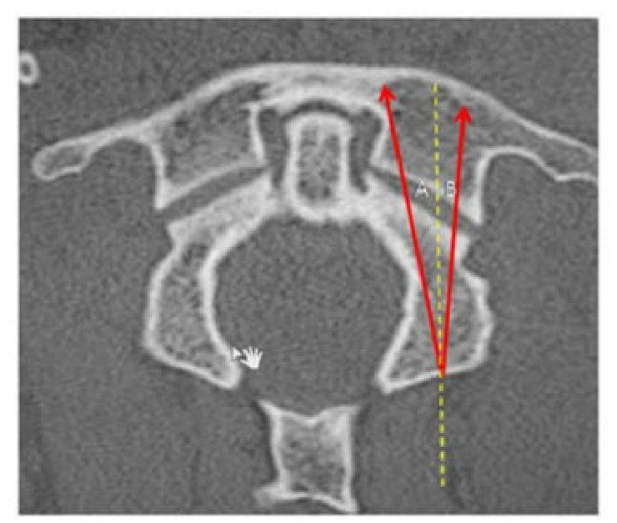

Fig. 2 Coronal view reconstruction of the atlanloaxial complex

From Fig. 2 coronal oblique reconstruction was performed parallel to the screw trajectory in the sagittal plane. Two 3.5 $\mathrm{mm}$ screw trajectory simulations were performed then the safe zone in the coronal view was measured by the angle between the most medial (A) and lateral (B) safe angles of the screw to the midline of the spinous process. 
The mean and SD for angle and length was recorded and analyzed on Microsoft Excel 2010 (Microsoft, Chicago, IL, USA). Statistical analysis was performed using IBM SPSS Statistics, version 19.0 (SPSS Inc., Chicago, Il, USA)

\section{Results}

The results of the measured angles of the safe zone for the screw trajectory are shown in Table 1. The average of safe angle in the sagittal plane was $51.25^{\circ}$ to $61.27^{\circ}$ from the superior articular surface of $\mathrm{C} 2$. The average safe angle in the coronal plane was $9.53^{\circ}$ medial and $4.26^{\circ}$ lateral to the midline.

Table 1. the measured angles of the safe zone for the screw trajectory

\begin{tabular}{ccccc}
\hline & \multicolumn{2}{c}{ Sagittal plane* } & \multicolumn{2}{c}{ Coronal plane* } \\
& Highest & lowest & Medial & lateral \\
\hline Mean & 61.26 & 51.65 & 9.53 & 4.26 \\
SD & 5.43 & 7.03 & 3.18 & 3.58 \\
\hline
\end{tabular}

safe angle for screw trajectory in sagittal and corronal plame

The result of the screw trajectory on $\mathrm{C} 2$ and the average screw lengths were reported in Table 2. The point of the screw trajectory that intersected $\mathrm{C} 2$ was safe and did not violate the vertebral foramen was $8.03 \mathrm{~mm}$ from the posterior of the superior articular surface of $\mathrm{C} 2$ and the ideal point of the screw trajectory intersection on $\mathrm{C} 2$ that created the longest path of the screw was $2.36 \mathrm{~mm}$

Table 2. the screw trajectory on $\mathrm{C} 2$ and the average screw lengths

\begin{tabular}{cccc}
\hline & \multicolumn{3}{c}{ Position and Length of screw* } \\
& Safe & Ideal & Iength \\
\hline Mean & 8.03 & 4.5 & 44.16 \\
SD & 2.07 & 1.08 & 3.57 \\
\hline * point of screw trajectory intersection C2 and screw length in millineter
\end{tabular}

\section{Discussion}

Atlantoaxial transarticular screws were pioneered by Magerl and Seeman in the 1970 s. This technique provides superior biomechanical properties and higher fusion rates and does not require postoperative halo immobilization, but has been reported to be the most dangerous form of fixation. The reported rates of vertebral artery injury range from $4.1 \%$ to $8.2 \%$. $^{(3)}$

Because the vertebral artery runs on the anterolateral side of the lateral margin of the screw when it passes the par interarticularis of $\mathrm{C} 2{ }^{(4)}$, the risk of injuring the vertebral artery is predictable by measuring the safe inclination of the screw trajectory reference from the superior articular surface of $\mathrm{C} 2$ and the safe zone in the coronal plane is predictable by measuring the medial and lateral deviations from midline that predicted the screw trajectory without violating the spinal canal and purchase in the $\mathrm{Cl}$ lateral mass.

From this study the safe zone for the screw trajectory was narrow in both the sagittal and coronal planes. The $\mathrm{C} 2$ isthmus has been found to be too narrow to accept a $3.5 \mathrm{~mm}$ screw in two of 75 cases. Based on these results, the pre-operative $\mathrm{CT}$ angiography with sagittal and coronal reconstructions should be obtained to determine the diameter of the isthmus that will allow the passage of the screw and to create the template of the screw trajectory.

The anatomical reduction of the atlantoaxial joint before screw insertion is very important. I Any amount of subluxation of the safe zone of the screw trajectory will be altered. Madawi et al. reported the malposition of the screw from incomplete reduction in 9 of 14 cases and 5 vertebral artery injuries were associated with incomplete reduction. ${ }^{(5)}$

From related studies, the anatomical risk of vertebral artery injury of the $\mathrm{C} 2$ transarticular screw and $\mathrm{C} 1-2$ transarticular screw did not significantly differ. ${ }^{(6,7)}$ The risk of vertebral artery injury is derived from several factors: (1)anatomy of the vertebral artery, ${ }^{(2)}$ malreduction of the C1-2 facet joint, ${ }^{(3)}$ narrowness of the $\mathrm{C} 2$ isthmus and ${ }^{(4)}$ improper surgical technique..$^{(3,8,9,10,12)}$ The preoperative plan of the ideal screw trajectory could decrease the risk of vertebral artery injury during surgery. ${ }^{(11)}$

In this research, we studied the safe zone of the screw trajectory in the sagittal and coronal planes using the reconstructed images from thin section $\mathrm{CT}$ scans. Therefore, future studies should apply these results in cadaveric studies and compare the risk of vertebral artery injury with standard techniques as well as the rate of malposition screws among these procedures.

\section{Conclusion}

The screw trajectories were studied by measuring the safe inclination in both the sagittal and coronal planes. The result of this study showed the narrow range of the safe zone for screw inclination and some $\mathrm{C} 2$ isthmus were too small for a 3.5 screw. A pre-operative evaluation using reconstruction $\mathrm{CT}$ scans should be performed to determine that the isthmus is wide enough for screw placement. 


\section{References}

1. Seeman MF. Posterior fusion of the atlas and axis by transarticular screw fixation, Cervical spine I, Springer Berlin; 1987. p. 322-7.

2. Grob D, Crisco JJ III, Panjabi MM. Biomechanical evaluation of four difference posterior atlantoaxial fixation technique. Spine 1992; 17: 480-90.

3. Peng CW, Chou BT, Bendo JA, Spivak JM. Vertebral artery injury in cervical spine surgery: anatomical considerations, management, and preventive measures. Spine J 2009; 9: 70-6.

4. Goel A, Gupta S. Vertebral artery injury with transarticular screws. J Neurosurg 1999; 90: 376-7.

5. Madawi AA, Casey AT, Solanki GA, Tuite G, Veres R, Crockard HA. Radiological and anatomical evaluation of the atlantoaxial transarticular screw fixation technique. J Neurosurg 1997; 86: 961-8.

6. Yoshida M, Neo M, Fujibayashi S, Nakamura T. Comparison of the anatomical risk for vertebral artery injury associated with the $\mathrm{C} 2$-pedicle screw and atlantoaxial transarticular screw. Spine (Phila $\mathrm{Pa}$ 1976) 2006; 31: E513-7.

7. Neo M, Matsushita M, Iwashita Y, Yasuda T, Sakamoto T, Nakamura T. Atlantoaxial transarticular screw fixation for a high-riding vertebral artery. Spine
(PhilaPa 1976) 2003; 28: 666-70.

8. Mandel IM, Kambach BJ, Petersilge CA, Johnstone B, Yoo JU. Morphologic considerations of $\mathrm{C} 2$ isthmus dimensions for the placement of transarticular screws. Spine (Phila Pa 1976) 2000; 25: 1542-7.

9. Paramore CG, Dickman CA, Sonntag VK. The anatomical suitability of the C1-2 complex for transarticular screw fixation. J Neurosurg 1996; 85: 221-4.

10. Bloch O, Holly LT, Park J, Obasi C, Kim K, Johnson JP. Effect of frameless stereotaxy on the accuracy of C1-2 transarticular screw placement. J Neurosurg 2001; 95: 74-9.

11. Jun BY. Anatomic study for ideal and safe posterior C1-C2 transarticular screw fixation. Spine (Phila Pa 1976) $1998 ; 23: 1703-7$.

12. Magerl F, Seemann PS. Stable posterior fusion of the atlas and axis by transarticular screw fixation. In: Kehr P, Weidner A, editors. Cervical spine. Wien: Springer-Verlag; 1986. p.322-7.

13. Abou Madawi A, Solanki G, Casey AT, Crockard HA. Variation of the groove in the axis vertebra for the vertebral artery. Implications for instrumentation. J Bone Joint Surg Br 1997; 79: 820-3. 